\title{
Alışveriş sözcüğü üzerine bir inceleme
}

Yasemin ÇÜRÜK1

\begin{abstract}
APA: Çürük, Y. (2019). Alışveriş sözcüğü üzerine bir inceleme. RumeliDE Dil ve Edebiyat Araştırmaları Dergisi, (17), 14-21. DOI: 10.29000/rumelide.656167.
\end{abstract}

\section{$\ddot{O} \mathbf{z}$}

Ticaret, ürün ve çeşitli hizmetlerin, para ile alım ve satım işlerinin tamamı veya takas yöntemiyle insanların arasında gerçekleşen ekonomik bir etkinliktir. Bunun için ticaret insanlık tarihi kadar eskiye uzanır. Bu durumda ticaretle ilgili sözcüklerin de her dilde bir o kadar eski olması kaçınılmazdır. Türkçeyi de bu bakımdan değerlendirdiğimizde, ticaretle ilgili pek çok sözcüğün Eski Türkçeden itibaren kullanıldığını görmek şaşırtıcı olmayacaktır. Dahası ticaretle ilgili pek çok Eski Türkçe sözcügün günümüzde de kullanıldığı görülmektedir. Örneğin; satıġçı "satıcı”, birim "borç” gibi bazı sözcükler değişime uğramıştır, ancak bütün değişimlere rağmen günümüzde de kullanılmaya devam etmektedir. Yine de Eski Türkçede olup da günümüzde yerini başka sözcüklere bırakan yapılar da bulunmaktadır. Bu noktadan yola çıkarak bu çalışmada ikileme yoluyla oluşmuş olan alşsveriş sözcüğü incelenmiştir. Bu sözcüğün yapısı, ortaya çıkışı ve hangi dönemlerde kullanıldığı üzerine genel bir değerlendirme yapılmıştır. Çünkü alışveriş sözcüğü, günümüzde yaygın olarak kullanılmasına ve hatta ikileme olarak kabul edilmesine rağmen eski bir sözcüktür. Bu çalışmada alışveriş sözcüğünün tarihine genel bir bakış atılmıştır. Bu sayede bu sözcüğün ne kadar eskiye dayandığını görmek mümkün olacaktır. Bununla birlikte alışveriş sözcügü yanında kullanılan ya da alışveriş sözcüğü yerine tercih edilen sözcükler de dikkat çekecektir. Çok geniş kapsamlı olmamasına rağmen elde edilen veriler bu alandaki tercihi de ortaya koyacaktır.

Anahtar kelimeler: Alışveriş, ikileme, ticaret, sözcük türetme, sözlükbirim.

\section{A research on the word "Alışveriş"}

\begin{abstract}
Trade is an economic activity that takes place between people the whole of products and services, purchase and sale by means of barter or money. For this reason, trade dates back to the history of humanity. In this case, it is inevitable that the words related to trade should be as old as each language. When we evaluate Turkish in this respect, it will not be surprising to see that many words related to trade have been used since Old Turkic. Moreover, it is seen that many Old Turkic words related to trade are still used today. For example; Some words such as satıgçı "seller" and birim "debt" have changed, but despite all the changes, they are still used today. Nevertheless, there are structures in Old Turkic which have been replaced by other words. From this point of view, in this study, the word alışveriş which was formed through reduplicated was examined. A general evaluation has been made on the structure, emergence and periods of this word. The word alışveriş is an old word, although it is widely used and even accepted as a reduplication. In this study, an overview of the history of the word alısveriş is given. In this way, it will be possible to see how old the word goes. However, in addition to the word shopping, the words used or preferred instead of the word shopping
\end{abstract}

1 Dr. Öğr. Üyesi, Doğuş Üniversitesi, Fen Edebiyat Fakültesi, Türk Dili ve Edebiyatı Bölümü (İstanbul, Türkiye), yasemincuruk@gmail.com, ORCID ID: oooo-0002-8650-2911 [Makale kaylt tarihi: 02.10.2019-kabul tarihi: 20.12.2019; DOI: $10.29000 /$ rumelide.656167] 
will also attract attention. Although it is not very comprehensive, the data obtained will reveal the preference in this field.

Keywords: Alışveriş, reduplication, trade, word-formation, lexeme.

\section{Giriş}

Ticaretin varlığı, insanlık tarihi kadar eskiye dayanır. Çünkü ticaret "ticaret kişi ya da toplumlarm kazanç sağlamak amacıyla giriştikleri ve bir yerden başka bir yere taşımak zorunda oldukları her türlü ham ya da işlenmiş mal, hizmet, değer, yiyecek gibi şeylerin alım satımın, değiştokuşunu kapsayan ekonomik bir etkinliktir." (Bozkurt 2002: 153). İnsanlar kendilerinde fazla olanı verip sahip olmadıkları ve ihtiyaçları olan şeyleri almak zorunda kaldılar. Yani başlangıçta değiş tokuş yapma yoluyla ihtiyaçlarını karşllyyorlardı. Bu yüzden de kendilerinde olanı verip kendilerinde olmayanı almak şeklinde karşılıklı gerçekleşmiştir. Alışveriş sözcüğünde karşılıklı olma durumu vardır. Buradan yola çıkarak alş̧veriş sözcüğünün tanımına bakmak gerekirse sözcük terimler sözlüğünde "Tecimsel olsun ya da olmasın bir nesneyi alıp verme işlemi.” şeklinde tanımlanmıştır. (BSTS / Tecim, Maliye, Sayışmanlık ve Güvence Terim 1972)

Güncel Türkçe Sözlük'te ise şöyle tanımlanmıştır:

“a. 1. tic. Satın alma ve satma işi, alım satım, muamele. 2. mec. İlişki, münasebet”.

Türkçe Sözlük'teki tanıma göre alma-satma işlemi dışında mecazi bir anlam da kazandığ görülen alışveriş sözcüğü aynı zamanda ilişki anlamına da gelmektedir. İşte bu yüzden topluluklar arasındaki ilişki artıkça alışveriş de artmıştır. Özellikle de yeni ticaret yollarının oluşması ilişki düzeyini arttırmış ve böylelikle ticaret giderek gelişmiştir. Ticaret yollarının oluşması ve ilişkilerin gelişmesiyle birlikte dillerde ticaretle ilgili sözcükler türemiş ve bu sözcüklerin sayısı giderek artmıştır. Bu noktada Türkçe üzerine bir inceleme yaptığımızda Türkçede de ticaretle ilgili sözcüklerin sayısı azımsanamaz. Özellikle de Eski Türkçe metinleri incelediğimizde ticaretle ilgili bazı temel sözcükler karşımıza çıkmaktadır. Caferoğlu’nun Eski Uygur Türkçesi Sözlüğünde ticaretle ilgili tespit ettiğimiz bazı sözcükler:

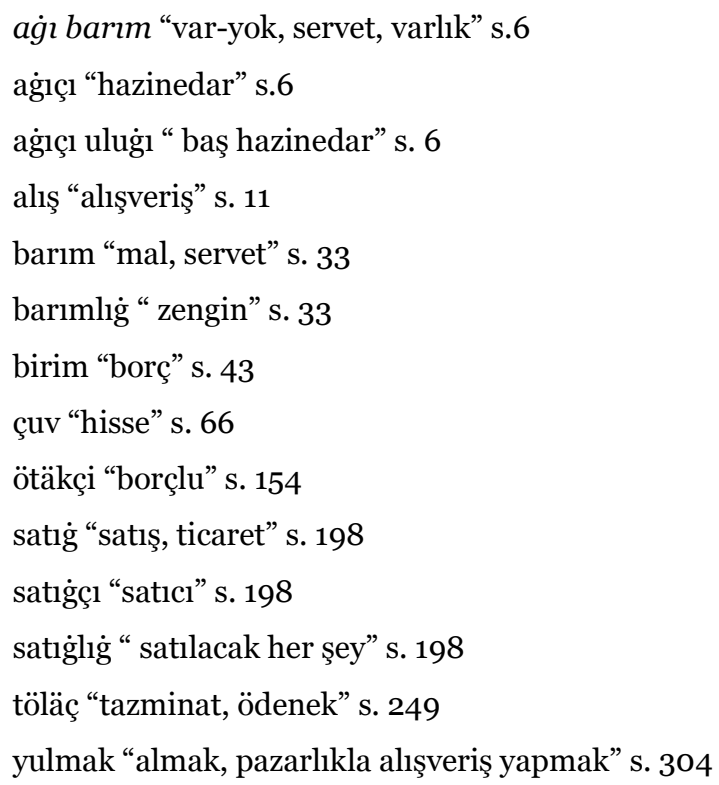




\section{İkileme nedir?}

İkileme, bazı araştırmacılarca anlamı kuvvetlendirmek amacıyla aynı sözcügün ya da eş ve zit anlamlı sözcüklerin tekrarı olarak tanımlanan ikileme (Hatipoğlu 1971: 9; Hengirmen 1995: 400- 409), bazı araştırmacılara göre ise sözcüklerin eksiz tekrar edilmesi olarak kabul edilir (Ergin 1972: 377-379; Bilgegil 1982: 162-163). Hatta ikileme kelimelerin ya da seslerin tekrarı şeklinde de tanımlamıştır (Topaloğlu 1989: 87; Vardar 1988: 125). Yani ikilemelerde anlamı kuvvetlendirmek esas olsa da ses ya da sözcük veya anlamsal bir tekrar, zitlık konusunda fikir birliği yoktur. İkilemenin evrensel tanımına göre ise ikileme söz ya da ses tekrarının olduğu yapılardır. Dahası sadece ses tekrarı olan ikilemelere kısmi (partial reduplication), sözcük tekrarı şeklinde olan ikilemelere ise tam (full reduplication) ikilemeler adı verilmektedir (https://wals.info/chapter/27). Buna göre Türkçede hem tam hem de kısmi ikilemeler vardır. Ayrıca Bauer'in tanımına göre de ikileme kökün veya bir parçasının tekrar edilmesiyle ortaya çıkan morfolojik bir süreç sonucundan oluşan yapılardır (2004: 90). Ancak bu tanımları incelediğimizde Türkçede yer alan anlamsal ikilemelerin ikileme kapsamına girmediği görülmektedir. Çünkü ikilemenin sözlük anlamını da ele aldığımızda ikileme, ses ya da sözcüğün aynen tekrarı dikkatimizi çeker. Online Türkçe Sözlük'te ikilemenin genel anlamının "İkilemek işi." Olarak verildiği görülmektedir (https://sozluk.gov.tr/). Yani mantıken ikilemelerde aynen tekrar esastır². Ayrıca ikilemeler tamamen kalıp ifadeler midir, değil midir sorgulanması gerekir. Tonlaması değiştikçe anlamı da değişir. Üstelik ikilemeler kalıplaşınca sözlükselleşme sürecine de girmiş kabul edilmektedir (Çürük 2016: 429). Sözlükselleşen örneklere biçerdöver, dedikodu gibi örnekler verilebilir. Bu makalenin konusunu oluşturan alışveriş sözcüğü de başlangıçta ikileme olarak kullanılmış olsa da kullanım sıklığından ötürü sözlükselleşmiş olabilir. Bu da aslında ikilemelerin türetim aracı olarak da kullanıldığının bir göstergesidir. Ancak normalde ikilemeler sözdizimsel yapılardır. Sözdizimsel yapılar kalıplaşmış değillerdir. Çünkü kalıplaşmış yapıları oluşturan sözcüklerin yerinin değişmemesi gerekir Çürük 2018: 500). İkilemelerde ise durum farklıdır. Her sözcük yinelenebilir. Bir ikileme kalıplaştıysa eğer sözlükselleşmiştir demiştik. Buna göre sözlükselleşen ikilemeleri, ikilemelerin yapısı birleşik sözcüklerin yapısına benzediği, yani en az iki sözcüğün bir araya gelmesiyle oluştuğu için birleşik sözcüklerin alt türlerinden sıralı birleşikler başlığı altında ele almak ve bu ikilemeler için "ikilemeli birleşik” teriminin kullanılması gerekebilir (Çürük 2017: 117-118)

\section{alsşveriş sözcüğünün tarihine genel bir bakış}

Eski Türkçe alşveriş sözcüğü bakımından incelendiğinde bazı metinlerde bu sözcüğün yer almadığı görülmüştür. Mesela Orhun Kitabeleri’nde alışveriş sözcüğüne rastlanmamıştır. Ancak yazıtlarda geçen "arkış tirkiş ısar" (KT G 8) ifadesi kervan göndermek, ticaret yapmak anlamında kullanılmaktadır (Alyılmaz 2004: 183). Bu durumda alışveriş sözcügünün yazıtlarda kullanılmamış olması bu sözcüğün o dönemde kullanılmadığı anlamına gelmez. Metni oluşturan kişinin üslubuna da bağlanabilir. Üstelik yukarıda verilen ticari terimler içinde alış ve yulmak şeklinde iki sözcük vardır. Bu iki sözcük alışveriş karşılığında kullanılır. Ancak metinlerde geçmiyor olması alsşveriş sözcüğünün olmadığını düşünmek doğru değildir. Dahası sivil Uygur metinlerinde alsşveriş sözcüğü kullanılmıştır. Gerek Clauson'un "An Etymological Dictionary of Pre-Thirteenth Century Turkish" adlı etimolojik sözlügünde gerekse de Çukurova Üniversitesinin Eski Türkçe ve Karahanl Türkçesinin Tarihsel Derlemi (7.-13. yy.)'nde alşveriş sözcü̆üu yer almaktadır. Derlemde bulunan örnekler aşağıda yer almaktadır:

\footnotetext{
2 Aslında bu konu “íkilemelerin Kapsamı” adlı makalede tartışılmıştır.
} 
satıg yul(ug) (Mai.Tek.o61.24) ogrınta ant antıḳtımız.. bir (Mai.Tek.o61.25) edig tavarıg alış bėriş ogrınta (Mai.Tek.061.26) öyi öni meyzin tegşürüp [Maitrisimit Nom Bitig (Hami)] (10-11. yy.) ${ }^{3}$ han sözledi (HT VI 8-24) samtso açari erser : idiz barḳdın (HT VI 8-25) önmiş dintar ol : yirtinçilüg (HT VI 8-26) törü-din itmiş (?) (HT VI 8-27) VI 9 /si/z-ni birle alış bẻriş yoụ : (Hsüen Tsang Biyografisi) 4

Clauson ise etimolojik sözlüğünde alş̧verişle ilgili olarak şu sözcüklere yer vermiştir:

alış "ahş̧veriş" (aynı zamanda vergi anlamındadır) Clauson, genelde ahş bèriş şeklinde bir öbek içinde kullanıldığını ve 8. yy. sivil Uygur5 metinlerinde hem alsş, hem alış bèriş hem de bériş sözcüklerine rastlandığını belirtmiştir (Clauson 1972: 152).

bėrim alım "alışveriş" (Clauson 1972: 145).

bẻriş “alışveriş" (Clauson 1972: 369).

Clauson'un sözlüğünde yer alan bilgilere göre alışveriş için alş, bèriş ve bérim alım yapıları kullanılmaktadır. Bu da aslında ticaretin yaygınlığını göstermektedir.

Radloff ise Versuch eines Wörterbuches der Türk-Dialecte'de alışveriş anlamına gelen alış sözcüğünden bahseder ve bu sözcüğün Osmanlı Türkçesinde, Kırım ve Uygur lehçelerinde kullanıldığını belirtir. Hatta örnek cümle ve kullanımlara da yer verir (1893: 382). Yani Radloff'un tespitine göre alışveriş için sadece alış sözcüğü tercih edilmiştir.

Karahanlı Türkçesi döneminde de alşveriş sözcüğü kullanılmıştır. Dîvânu Lûgâti’t-Türk ve Kutadgu Bilig'de alışveriş sözcüğüne dair bilgiler aşağıda yer almaktadır:

\section{Dîvânu Lûgâti't-Türk'te ahş bèriş: Bir hakkı alma verme, (alsş veriş) (I, 62/16).}

Kutadgu Bilig'de ise alış hem biriş (alış-veriş, ticaret; ilişki, münasebet) (krş. DTS 36a: alış beriş; ED 152a) şeklinde karşımıza çıkar (Arat 1947: 432, 444).

4305: saya ten tuşuy birle èltiş barış katıtlgıl ḳarılġıl alış hem bẻriş

"Sen kendi akranlarını sık sık ziyaret et; anlara katıl ve onlar ile ilişkini kesme" (Ölmez 1997: 24).

"Sen kendi akranlarını ziyaret et; onlara katıl ve alışverişte bulun" (Taş 2012: 82)

4421: .... alış hem biriş

Eski Anadolu Türkçesi döneminde ise alışverişs sözcüğüne rastlanmamıştır. Onun yerine benzer olsa da başka bir yapının tercih edildiği görülmektedir: ah sat, ah sat etmek. Tarama Sözlüğü’nü taradığımızda alş̧veriş kavramı için alı satı ve alım satım sözcükleri karşımıza çıkmıştır.

ah sath, (alım satım) "Alışveriş, ticaret."

\footnotetext{
3 (http://derlem.cu.edu.tr/index.php?a=tarihsel\%2Fsearch\&term=al\%C4\%B1\%C5\%9F+b\%C4\%97ri\%C5\%9F\&donem $=\&$ eser_adi $=$ \&yuzyil $=\&$ metin_turu $=$ )

4 (http://derlem.cu.edu.tr/index.php?a=tarihsel\%2Fsearch\&term=al\%C4\%B1\%C5\%9F+b\%C4\%97ri\%C5\%9F\&donem $=\&$ eser_adi $=$ \&yuzyil $=\&$ metin_turu $=$ )

5 Bu metinler, Wilhelm Radloff un Uigurische Sprachdenkmaler adıyla yayımladığı ve içinde 128 belgenin olduğu kitapta yer almaktadır.
} 


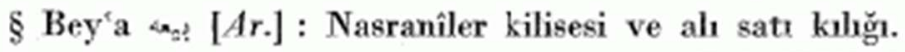

(B̈ab. XVI. 1, 141)

§ Kâsid كأس [Ar.] : Alı satı

(Bab. XVI. 1, 470)

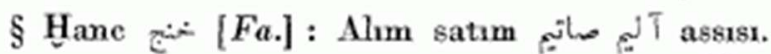

(Samil. XVI. 425)

alı satı etmek, (alım satım etmek, alı satı eylemek, alı satı eyleşmek) "Alışveriş yapmak."

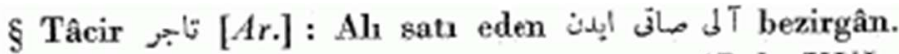

(Bab. XVI. 2, 21)

§ Teserruk تسرق [Ar.] : Bir yerde halk alı satı etmek, bazarlanmak.

(Bab. XVI. 2, 329)

§ Nefislerinizi cennete satup Allah ile ah satı eyleşdüğüñüze dآث إيلشدكوكزه sevinişünüz.

(Rahat. XVI. 30)

$\S$ Hiç bir kimesne kapusmı açup dahi çıkup benüm ile alı satı eylemedi الل صانى إيلهدى

(Rahat. XVI. 128)

§ Bundan akdem mezburlar ile nice zaman buğday verip akça alıp hayli alım satım itmiş ايتش صاتم idik.

(Sic. A. XVI. 4, 266)

§ Urmûn ارمون أرa.] : Sifte ki alım ve satım etmekte إيتهكد. isti'mâl olunur.

(Ni'meti. XVI. 102)

Güngör'ün Memluk Kipçak Türkçesinde İkilemeler adlı makalesindeki örnekler arasında alsşveriş sözcüğü yer almamaktadır (Güngör 2018: 116-117). Bunun sebebi alışveriş sözcüğünün ikileme olarak değerlendirilmemiş olması olabilir. Yukarıda yapılan açıklamalara istinaden ikilemeler tam kalıplaşmış yapılar değildir, eğer tam kalıplaşırsa sözlükselleşip bağımsız bir sözlükbirim olarak kullanılabilir. Ayrıca diğer bir açıklamaya göre ise alşseriş sözcüğünün kullanılmamış olduğu ya da alışveriş anlamında başka bir sözcük kullanıldığı anlamına da gelebilir.

Gerek Nehcü’l-Ferâdiŝ gerekse Atabetü'l-Hakayık'ta alışveriş sözcüğüne rastlanmamıştır. Ancak bu metinlerde alşveriş yerine başka sözcükler tercih edilmiş olabilir.

Çağatayca sözlük Senglah'ta ise alışveriş sözcüğü yoktur, ancak benzer bir yapı olan ahı̇ satıg sözcüğü karşımıza çıkmaktadır (Eckmann 2009: 51).

\section{alsşveriş sözcüğünün yapısı}

al-(1)ş+ver-(i)ş= alışveriş

İsim-fiil eki olan -ş ekini alan almak ve vermek fiillerinin birleşmesiyle oluşmuştur. - ş eki de -ma ve mak gibi iş ifade eden fiil adı türetir. Üstelik Uygurca metinlerde de, Karahanlı Türkçesinde de bu sözcük benzer şekilde yer almaktadır. Tek fark ses değişimidir: alş̧ bèriş.

Günümüzde alş̧veriş, ikileme olarak kabul edilir. Ancak tam ikileme değil, kısmi ikileme olarak değerlendirmek daha doğru görünse de yine de bu yapı, Uygur döneminden beri var olduğuna göre ikileme olarak kabul edilmeli midir? Çünkü bir yapının ikileme olarak kullanmak demek anlamı 
pekiştirmek demektir. İkilemenin tanımına göre bu sözcüğü incelediğimizde ses tekrarı olmasına rağmen alışveriş örneğinde anlam pekiştirilmemiş, onun yerine bir kavrama karşılık olarak kullanılmıştır. Üstelik bu yapının oldukça eski olması ve günümüzde sözlük maddesi olarak yer alması da alş̧veriş sözcüğünün ikileme değil sözlükbirim olduğunun göstergesi olarak kabul edilebilir. Çünkü bu yapı kalıplaşmıştır. Yani sözlüksel bir yapıdır. Belki başlangıçta ikileme olarak ortaya çıktıysa da artık ikileme değil sözlükbirimdir. Bu durumda bu yapı ikilemeli birleşik sözcüktür.

\section{Sonuç}

alışveriş sözcüğü üzerine yapılan bu çalışmada, ikilemenin tanımı ile özelliklerinden, alşveriş sözcügünün yapısı ile anlamından, incelenen bazı temel metinler ve sözlüklerden yola çıkılarak aşağıda yer alan tespitlere ulaşılmıştır:

Buna göre alışveriş sözcüğü son dönemlerde türetilmiş bir sözcük değildir.

İkilemenin tanımından yola çıkılarak alışveriş sözcügü başlangıçta ikileme olarak kullanılmış olsa da artık ikileme değildir. Bir kavrama karşllık geldiği ve sözlüksel bir boşluğu doldurduğu için sözlükbirimdir. Ayrıca birleşik sözcüğün alt türlerinden sıralı birleşikler başlığı altında değerlendirilip ikilemeli birleşik olarak kabul edilebilir.

alş̧veriş sözcüğünün Uygur dönemine dayanan bir tarihçesi olduğu tespit edilmiştir. Hatta Clauson’a göre bu sözcüğün 8. yy’a kadar uzanan bir tarihçesi söz konusudur.

Orhun Kitabeleri’nde bu sözcüğe rastlanmamıştır.

Karahanlı Türkçesinde bu sözcügün kullanıldığı tespit edilmiştir. Buna göre alışveriş sözcüğü Kutadgu Bilig'de alış hem biriş, Dîvânu Lûgâti't-Türk'te alış bẻriş şeklinde karşımıza çıkmıştır.

Radloff un Versuch eines Wörterbuches der Türk- Dialekte I sözlüğünde alş̧ maddesi altında alşveriş sözcüğüne yer verdiği ve bu yapının Osmanlı Türkçesi, Kırım ve Uygur lehçelerinde olduğunu belirttiği tespit edilmiştir.

Tarama Sözlügü’nün taranması sonucu Eski Anadolu Türkçesi döneminde alşverişs sözcüğü yerine alı satı ve alım satım yapılarının tercih edildiği görülmüştür.

Nehcül-Ferâdiŝ ve Atabetü'l-Hakayık'ta da alışveriş sözcügüne rastlanmamıştır.

Görüldüğü üzere alş̧veriş sözcüğü, oldukça eski bir yapıdır. Üstelik çok fazla ses değişimine de uğramamıştır. Sadece bazı dönemlerde alım satım, alış, veriş gibi alışverişi karşılayan yapılar kullanılmıştır. Buna rağmen alş̧veriş sözcüğünün kökeni Eski Türkçeye dayanmaktadır. Günümüzde de sıklıkla kullanılan bu sözcük, Türkçede ikileme yoluyla sözcük türetiminin ne kadar eskiye dayandığının da bir göstergesidir. Çünkü ikilemeler kalıcı yapılar değildir, geçici yapılar oluşturur. ikilemeler biçimbilimin değil, sözdizimin konusudur. İkilemelerin kurulma amacı anlamı kuvvetlendirmek olduğu için her sözcüğün ikileme olarak kullanılması mümkündür. Ancak bir ikilemenin kalıcı yapılar oluşturması demek ikilemenin bir söz yapım aracı olarak kullanıldığını gösterir. 
bu durumda da bu tür yapıları sıralı birleşik sözcüğün alt dalı olan ikilemeli birleşik sözcük olarak değerlendirmek daha doğru olacaktır. ${ }^{6}$

\section{Kaynaklar}

Aktan, B. (2010). "Divanü Lügâti’t-Türk’te İkilemeler”. Selçuk Üniversitesi Türkiyat Araştırmaları Enstitüsü Türkiyat Araştırmaları Dergisi, 28 (Güz), 1-12.

Alyılmaz, C. (2004). İpek Yolu ve Orhun Yazıtları. A.Ü. Türkiyat Araştırmaları Enstitüsü Dergisi. Sayı 24, S. 181-192.

Arat, R. R. (2006). Atabetü'l-Hakayık, Ankara: TDK Yayınları.

Ata, A. (1998). Nehcü’l-Ferâdîs III Dizin- Sözlük. Ankara: Türk Dil Kurumu Yayınları.

Atalay, Besim (1998-1999). Dîvânu Lûgâti’t-Türk Tercümesi I-IV, Ankara: Türk Dil Kurumu Yayınları. 4. bs.

Bilgegil, K. (1982), Türkçe Dilbilgisi, İstanbul: Dergah Yayınları.

Bozkurt, N. (2002). Ticaretin Felsefesi, Tarihçesi Ve Etikle Olan Sıkı Bağına İlişkin Bazı Saptamalar. İstanbul Ticaret Üniversitesi Dergisi 2, s. 153-179.

Clauson, S. G. (1972). An Etymological Dictionary of Pre-Thirteenth-Century Turkish, Oxford: Oxford University Press.

Çürük, Y. (2016). İkilemelerin Kapsamı. Akademik Sosyal Araştırmalar Dergisi, Yıl: 4, Sayı: 29, Ağustos 2016, s. 426-430.

Çürük, Y. (2017). Türkçede Birleşik Sözcükler: İsimler. Basılmamış Doktora Tezi. Ankara Üniversitesi Sosyal Bilimler Fakültesi Türk Dili ve Edebiyatı Yeni Türk Dili Bilim Dalı.

Çürük, Y. (2018). Sözcük Türetme Yöntemi Olarak İkileme, International Journal of Languages' Education and Teaching. Cilt 6, Sayı 3, s. 499-503.

Dilçin, C. (1983). Yeni Tarama Sözlüğü. Ankara: Türk Dil Kurumu Yayınları.

Eckmann, J. (2009). Çağatayca El Kitabı (Çev. Prof. Dr. Günay Karaağaç). İstanbul: Kesit Yayınları.

Ergin, M. (1972), Türk Dil Bilgisi, İstanbul: İstanbul Üniversitesi Edebiyat Fakültesi Yayınları.

Ergin, Muharrem (2002). Orhun Abideleri. İstanbul: Boğaziçi Yayınları.

Güngör, O. C. (2018). Memlük Kıpçak Türkçesinde İkilemeler. Jass Studies- The Journal of Academic Social Science Studies, Doi number:http://dx.doi.org/10.9761/JASSS7440, Number: 65, Spring I 2018, p. 105-122.

Hatipoğlu, V. (1971). Türk Dilinde İkileme. Ankara: TDK Yayınları: 328.

Hengirmen, M. (1995). Türkçe Dilbilgisi. Ankara: Engin Yayınevi

Ölmez, Z. (2007). “Kutadgu Bilig'de İkilemeler (1)”, Türk Dilleri Araştırmaları, 7, s. $19-40$.

Radloff, W. (1893). Versuch eines Wörterbuches der Türk- Dialekte I (1893), S. Petersburg.

Taş, İ. (2012). “Kutadgu Bilig'de İkilemeler”. Türk Dili Araştırmaları Yıllığı Belleten, 2, 43- 95.

Topaloğlu, Ahmet (1989). Dilbilgisi Terimleri Sözlüğü, İstanbul: Ötüken Yayınları.

Vardar, B. (1988). Açıklamalı Dilbilim Terimleri Sözlüğü, İstanbul: ABC Kitabevi.

http://www.tdk.gov.tr/index.php?option=com_gts\&arama=gts\&guid=TDK.GTS.5a9fea6716dee5·3312 6336 07.03.2018 tarihinde erişildi.

http://derlem.cu.edu.tr/index.php?a=tarihsel\%2Fsearch\&term=al\%C4\%B1\%C5\%9F+b\%C4\%97ri\%C5 $\% 9 \mathrm{~F} \& d o n e m=\&$ eser_adi=\&yuzyil=\&metin_turu $=19.07 .2018$ tarihinde erişildi.

\footnotetext{
6 Ayrıntılı bilgi için bkz. Türkçede Birleşik Sözcükler: İsimler.
} 
http://www.tdk.gov.tr/index.php?option=com_tarama\&view=tarama\&kategori1=veritbn\&kelimesec= 394 23.07.2018 tarihinde erişildi.

https://sozluk.gov.tr/ 26.11.2019 tarihinde erişildi.

https://wals.info/chapter/27 26.11.2019 tarihinde erişildi. 